\title{
An Optimization Model for Environmental Ergonomics Assessment in Bioproduction of Food SMEs
}

\author{
Mirwan Ushada $^{1 *}$, Hani Febri Mustika ${ }^{2}$, Aina Musdholifah $^{3}$, Tsuyoshi Okayama $^{4}$ \\ 'Department of Agro-industrial Technology, Faculty of Agricultural Technology, Universitas Gadjah Mada, Yogyakarta, Indonesia \\ ${ }^{2}$ Research Center for Informatics, Indonesian Institute of Sciences (LIPI), Bandung, Indonesia \\ ${ }^{3}$ Department of Computer Sciences and Electronics, Faculty of Mathematics and Natural Sciences, Universitas Gadjah Mada, \\ Yogyakarta, Indonesia \\ ${ }^{4}$ Department of Regional and Environmental Science, College of Agriculture, Ibaraki University, Japan
}

\section{ARTICLE INFO}

Article history:

Received January 8, 2019

Received in revised form July 15, 2020

Accepted July 20, 2020

\section{KEYWORDS:}

Environmental Ergonomics,

Genetic Algorithm,

Set-points,

Bioproduction,

Food SMEs

\begin{abstract}
Environmental ergonomics in bioproduction of food Small Medium-sized Enterprises (SMEs) become a concern and need to be optimized. An optimization model was developed using a Genetic Algorithm (GA). The weight of an Artificial Neural Network Model was used as a fitness function for GA. The research objectives were: 1) To design an environmental ergonomic assessment system for bioproduction of Food SMEs, 2) To develop an optimization model for environmental ergonomic assessment using a Genetic Algorithm. GA is utilized to search optimal set points of environmental ergonomics based on the predicted fitness values. Each chromosome of GA represents the environmental ergonomics value. The parameters were heart rate, bioproduction temperature, distribution of bioproduction relative humidity and light intensity. The target of the optimization model was the bioproduction temperature set points. The research result indicated the model generated optimum values of environmental ergonomics parameter in bioproduction of food SMEs. The parameters could be used to provide standard workplace environment for the sustainability of food SMEs.
\end{abstract}

\section{Introduction}

SMEs is the labor-intensive industry in Indonesia. SMEs organization consists of several household workstation which integrate worker, material, and machinery. Workstation of food SMEs have several specific characteristics as 1) narrow layout of space, 2 ) high density of worker in workstation, 3) old-type machinery/equipment, 4) various type of bioproduction process, and 5) dynamic environmental ergonomics. The importance of environmental ergonomics for industry was highlighted on previous research (Parsons 2000). Parsons has suggested the significance of environmental ergonomics to optimize the environment based on workstation responsiveness (Parsons 2000).

Environmental ergonomics were initially introduced to Indonesian Food SMEs as one of the scopes of digital ergonomics (Ushada 2019). Digital ergonomics is an application of information technology for affective ergonomics assessment and based on sensor utilization, database, and/or internet (Ushada 2019). The initial

\footnotetext{
* Corresponding Author

E-mail Address: mirwan_ushada@ugm.ac.id
}

survey (Ushada 2019) indicated the interest level of SMEs owner to apply digital ergonomics as an appropriate technology for work system of Indonesian Agroindustry. The previous research concluded the characteristics of digital ergonomic invention as (Ushada 2019): 1) data measurement, 2) design of conceptual system, 3) development of artificial intelligence model, 4) converting the weight of model to hardware, and 5) finalizing the sensor prototype.

Parsons suggested four methods to identify environmental ergonomics using subjective methods, objective measures, behavioral methods, and modelling (Parsons 2000). Based on that suggestion (Parsons 2000), Ushada et al. have identified environmental ergonomics control system for Indonesian SMEs (Ushada et al.2017a).Ushada et al. have developed the modelling of affective temperature control using Artificial Neural Network (ANN) (Ushada et al. 2017b). Based on this modelling, hardware of Kansei Engineering-based Sensor for Agro-industry (KESAN) has designed to control environmental ergonomics (Ushada et al. 2016). This sensor of KESAN completed the previous development of digital ergonomics to assess integrated workload (Ushada et al. 2016) and (Ushada et al. 2017c). Ushada 
also concluded that digital ergonomic is expected to integrate the data of workload, supporting equipment, and environmental ergonomic for the sustainability of SMEs (Ushada 2019).

Parameter standardization of environmental ergonomics is required to support the quality control of digital ergonomics in food SMEs. There are various environmental ergonomics-related standards or rules which was developed by government. SNI or National Standard of Indonesia (Anonym 2003) has stated the threshold for temperature set points as light workload $\left(30^{\circ} \mathrm{C}\right)$, medium workload $\left(26.7^{\circ} \mathrm{C}\right)$, and heavy workload $\left(25^{\circ} \mathrm{C}\right)$. Regulation of Ministry of Energy and Mineral Resources (RMEMR) No. 13 Year of 2012 has stated, according to SNI, the transit room or lobby temperature is between 27 to $30^{\circ} \mathrm{C}$ (Anonym 2012).

Optimization is an appropriate modelling method to identify the standard parameters of environmental ergonomics. Wongwien and Nanthavanij have developed a mathematical model for scheduling based on problem of multi-objective scheduling and ergonomics workface (Wongwien and Nanthavanij 2017). Delgoshaei and Ali have combined hybrid Ant Colony Optimization and Tabu Search for location-allocation of skilled workers in systems of cellular manufacturing (Delgoshaei and Ali 2017). Ushada and Okayama have developed the tradeoff between green and affective work system for food SMEs (Ushada and Okayama 2016). Besides, Ushada and Okayama have used simulated annealing to optimize environmental parameter for the purpose of SME worker affective index (Ushada and Okayama 2016). However, none of these research are applicable to assess environmental ergonomics in bioproduction of food SMEs.

There are various methods for optimization as Genetic Algorithm, Simulated Annealing, Particle Swarm Optimization and Ant Colony Optimization. Genetic Algorithm is a simple and powerful algorithm to identify environmental set point. Yang et al. have used genetic algorithm to find the optimal set point of condensing temperature in air-cooled chillers (Yang et al. 2015). Ma et al. have used genetic algorithm to optimize comprehensive energy consumption (Ma et al. 2017).

This research proposes an environmental ergonomics assessment system for food SMEs. The parameter of environmental ergonomics set point in food SMEs was identified to support the assessment system. The ultimate research goal is to introduce the appropriate technology of environmental ergonomics to the society of food SMEs in Indonesia. The research objectives are: 1) to design an environmental ergonomic assessment system for bioproduction of Food SMEs, 2) to develop an optimization model for environmental ergonomic assessment using genetic algorithm. The research benefit is to provide standard of environmental ergonomics parameters for the sustainability of food SMEs.

\section{Materials and Methods}

\subsection{Environmental Ergonomics System}

The design (Table 1) involves eight subsystems as regional labor offices, cluster of SMEs, control system, ANN model, optimization model, KESAN $1^{\text {st }}$ Generation, $2^{\text {nd }}$ Generation, and wages model. Figure 1 indicates the design of environmental ergonomics assessment system for bioproduction of food SMEs. The design is expected to be applied in Indonesian food SMEs. The amenities of system consist of three main functions as monitoring, control, and assessment functions.

The monitoring function is pursued by regional labor offices. Regional labor offices is an administration office under regional government which in charge of human power management. The office task is monitoring and empowering the SMEs community. The environmental ergonomics control system is utilized based on the previous research (Ushada et al. 2017b). The result of control system is identified based on the map of ANN model (Ushada et al. 2017b). In this paper, the optimization model is designed based on genetic algorithm for providing environmental ergonomics parameters. These parameters are important for further ergonomic assessment. GA determines environmental ergonomics parameters as heart rate, indoor temperature, distribution of relative humidity, and light intensity based on various standard of temperature set points (Table 2). Environmental ergonomics set points are the input for KESAN $2^{\text {nd }}$ generation. Ergonomic assessment system is integrated based on KESAN $1^{\text {st }}$ generation (Integrated workload assesment system), $2^{\text {nd }}$ generation, optimization model, and wages model. The expected output of system is categorized as status of poor, medium, and good ergonomics. The output will be a feedback for employees' social security systems for the monitoring functions by regional labor offices.

Table1. Sub-systems of integrated ergonomic assessment

\begin{tabular}{ll}
\hline Sub-systems & References \\
\hline Regional labour offices & Govermental function \\
SMEs Cluster & Cooperatives-like organization \\
Control system & (Ushada et al. 2017a) \\
ANN model & (Ushada et al. 2017b) \\
Optimization model & This research paper \\
KESAN 1st generation & (Ushada et al. 2016) \\
KESAN 2nd generation & (Ushada et al. 2017) \\
Wages model & (Ushada and Okayama 2016) \\
\hline
\end{tabular}




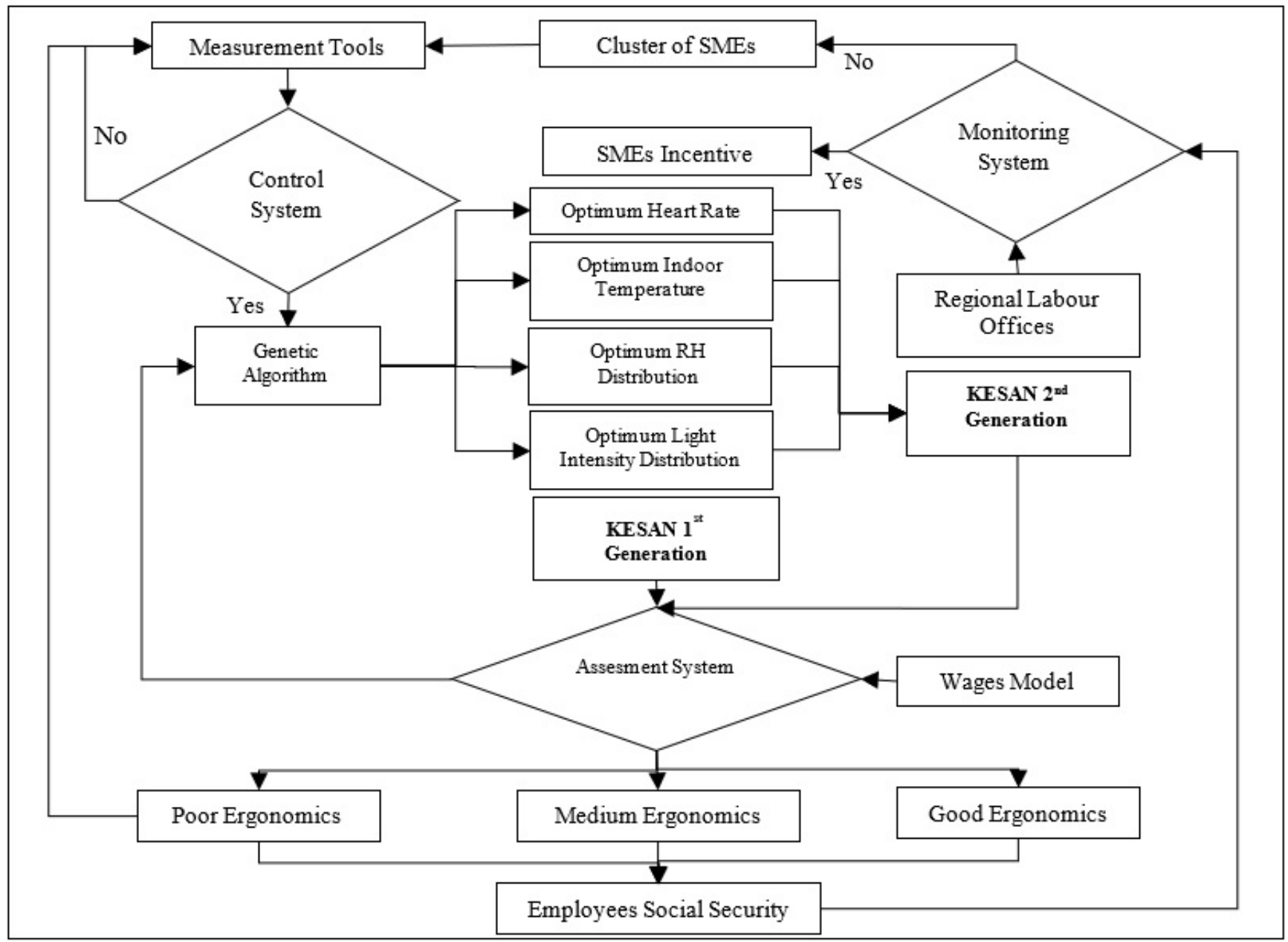

Figure 1. Design of environmental ergonomic assessment

Table 2. Target of bioproduction temperature set points

\begin{tabular}{cl}
\hline Temperature $\left({ }^{\circ} \mathrm{C}\right)$ & References \\
\hline 27.5 & (Ushada et al. 2017b) \\
28.0 & (Anonym 2002) \\
28.5 & (Ushada et al. 2017b) \\
28.8 & (Ushada et al. 2017b) \\
29.0 & (Ushada et al. 2017b) \\
29.3 & (Ushada et al. 2017b) \\
29.5 & (Ushada et al. 2017b) \\
29.8 & (Ushada et al. 2017b) \\
30.0 & (Anonym 2003) \\
31.1 & (Ushada et al. 2017b) \\
\hline
\end{tabular}

\subsection{Methodology}

Figure 2 describes the research methodology of Genetic Algorithm. The Genetic Algorithm is utilized to find the optimal environmental ergonomics parameters based on target temperature in Table 2. Optimization process is initiated using parameter setting. Parameter setting covers the chromosome length (g), amount of population ( $\mathrm{p})$, amount of generation or iteration (i), fitness function $(\mathrm{f}(\mathrm{k})$ ), mutation probability $(\mathrm{p}$, $\mathrm{m})$ and crossover probability $(\mathrm{p}, \mathrm{c})$. Initialization of population is pursued based on amount of population (p), and chromosome length (g). Evaluation process calculates the fitness value of each chromosome using the fitness function of ANN model (Ushada et al. 2017b). Stopping criterion is based on iteration, error and, combined error and iteration. Parental selection is based on roulette wheel selection to select parental chromosome in crossover. Crossover and mutation is based probability crossover ( $p_{-} c$ ) and mutation (p_m). Subsequently, new chromosome (offspring) was generated. Generation was updated using new population. The objective of new population is based on elitism to validate chromosome with satisfactory fitness value is the continually input to the next generation. If the stopping criterion is fulfilled, the optimal parameter of environmental ergonomics is determined based on the best fitness value. 


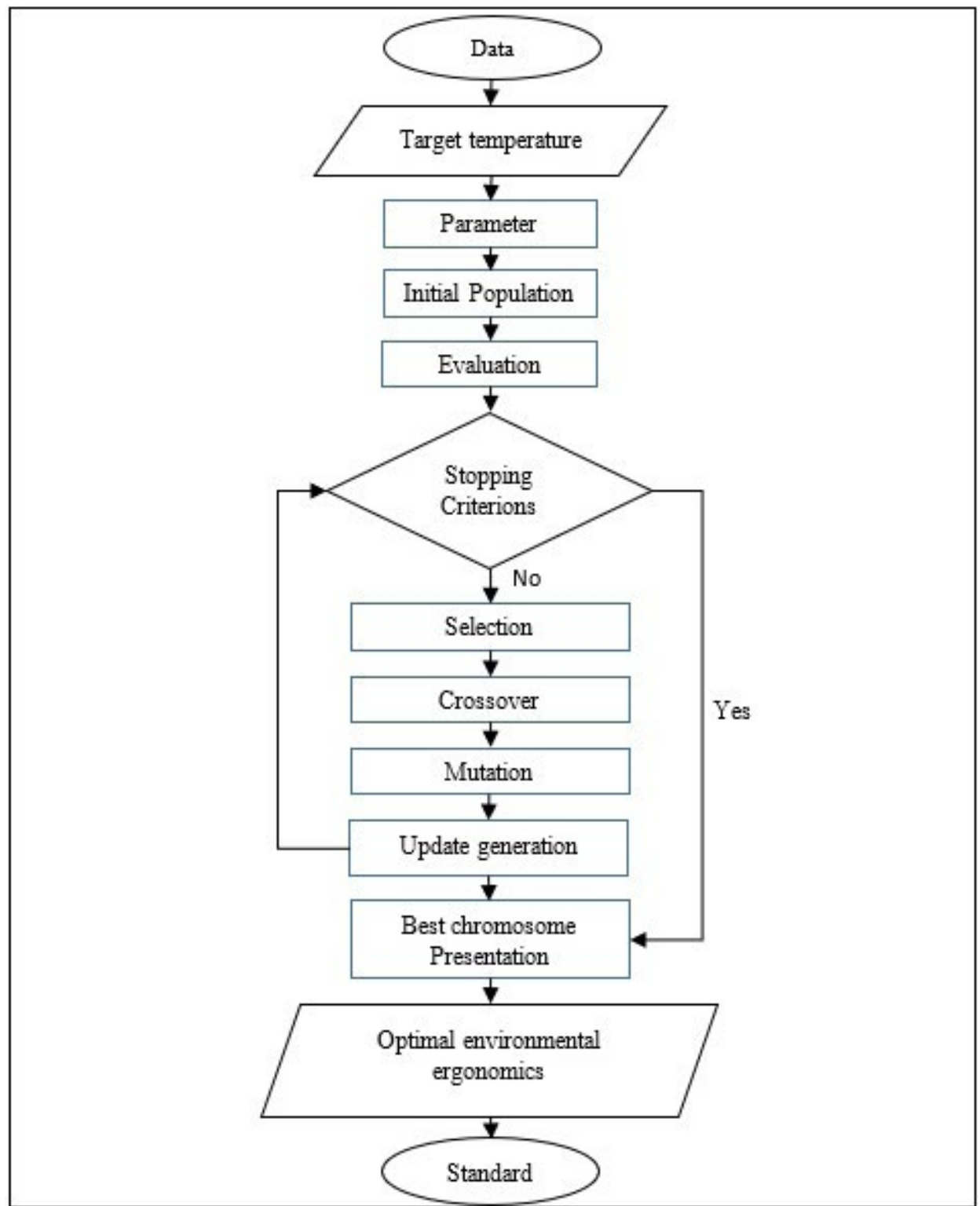

Figure 2. Methodology of genetic algorithm

\subsection{Schema of GA System}

Genetic algorithm application was developed using java programming language. Scheme of GA System is described as follow:

Population initialization

Initial population of GA is required to generate randomly before applying genetic operators. Population of GA consist of the number of chromosome as well as alternative of solutions. Thus, set of the environmental ergonomics parameters are coded as the representation of each chromosome. The environmental ergonomics parameters are heart rate, indoor temperature, relative humidity before working, relative humidity after working and light intensity. The representation of chromosome is indicated in Figure 3.

\section{Evaluation}

Evaluation is pursued on each chromosome by calculating the fitness value. Fitness function was calculated using the weight of ANN based on the previous research (Ushada et al. 2017b). The process was described in Figure 4.

The structure of ANN consist of an input layer, a hidden layer and an output layer (Ushada et al. 2017b). Normalization is carried by chromosome on input layer, to hidden layer for the process sum product and activation function (sigmoid) and for output layer on process of sum product and finally repeat to activation function (sigmoid).

Each layer consist of several neuron with each weight. Weight based on ANN model can be described as follow: 
1. Weight hidden layer to input layer (wHidIn) $\{-6.55266717885901,-9.5851806368075$, 5.79206581821694, -2.47939717519317, $-25.0832735625677\},\{-0.277023083217609$, $-13.5947845693249,-31.6589141928413$, $10.5211894049401,-10.32294162178\}$, $\{-1.25119248744866,3.19795750924082$, -8.3341928717707, 0.130036358461878, $5.61533948832036\},\{-6.06389305016582$, $-6.53008608250825,-5.17840857118516$, 12.4604013202245, -4.90172709176336\}, $\{-2.44564251537348,-4.33022806217884$, $-12.2820145158975,0.433235372117688$, $12.9392387925541\},\{-13.7651617088847$, 21.9978678356248, -22.3510014234378, $8.59485813350159,-6.21179190225034\}$, $\{8.3977656820259,-6.93433935254814$, $-1.88327607943757,-6.45558972947508$, $-1.73319023822086\},\{-7.19787121821834$, $-22.1166614089455,-13.269728338763$, $14.1880147066253,20.2027809928651\}$, $\{3.6731956075246,0.160595797525016$, $-5.14672470776692,-0.059102266988604$, $-44.3666940454452\},\{-3.18010818969$, $-1.98461744652256,-2.30670258722557$, $1.16035013381136,2.55076038057419\}$, $\{1.02836628633061,-11.2719005272418$, -3.39026757643561, 3.5370873022793, $-3.27637564217907\},\{-2.79271342893378$, $-1.9702322802789,-4.65169134069115$, $1.34156742513814,32.9690112830791\}$

2. Weight from output layer to hidden layer (wOutHid) $\{-3.47475911581204,-24.5922551791513$, 22.0028238324658, 2.76596562857797, $-11.5479825571178,-2.12229903852415$, 2.80419783404552, 3.32503233376351, $-3.97412706634657,-7.0753673260141$, $-2.54096647194149,-3.34050441544169\}$
Final calculation is pursued using equation from the previous research as follow in equations 1 and 2 :

$$
\mathrm{s}=\log \left(\frac{\text { input }}{1 \text {-input }}\right)
$$

Temperature set points $=\left(0.2875 \mathrm{x} \mathrm{s}^{4}\right)-\left(0.5344 \mathrm{x} \mathrm{s}^{3}\right)$ $-\left(0.0577 \times \mathrm{s}^{2}\right)-(2,269 \times \mathrm{s})+28,878$

Pseudocode of genetic algorithm can be described as follow:

1. population

2. population_size $\leftarrow 10$

3. chromosome_length $\leftarrow 5$

4. stopping_creation $\leftarrow$ iteration or absolute error

5. stop $\leftarrow 0$

6. for $\mathrm{i}=1$ to population_size do chromosome[i] for $\mathrm{c}=1$ to chromosome_length do

end for fill_chromosome[i]gen[c]

population $\leftarrow$ chromosome[i]

end for

7. while stopping_creation $>=$ stop do fitness(population) //evaluation step selected_chromosome $\leftarrow$ roulletewheel (population) //selection step crossover(selected_chromosome) mutation(population) best_chromosome $\leftarrow$ bestchromosome (population) new_stop $\leftarrow$ update(stop) stop $\leftarrow$ new_stop end while

8. best_chromosome

Implementation

Optimization using Genetic Algorithm is developed using java programming languange. The specification of software in this research is described as follow:

\begin{tabular}{|c|c|c|c|c|}
\hline $\begin{array}{c}\text { Heart rate after } \\
\text { working }\end{array}$ & $\begin{array}{c}\text { Bioproduction } \\
\text { temperature }\end{array}$ & $\begin{array}{c}\text { RH before } \\
\text { working }\end{array}$ & $\begin{array}{c}\text { RH after } \\
\text { working }\end{array}$ & $\begin{array}{c}\text { Light } \\
\text { intensity }\end{array}$ \\
\hline
\end{tabular}

Figure 3. Representation of chromosome 
1. Operation system Windows 10 pro 64-bit

2. Eclipse Kepler

3. XAMPP for Windows version 1.7.2

4. Play Framework 1.2 .5

5. Web browser (Chrome)

The specification of hardware is defined as computer or personal computer with at least processor Intel(R) Core(TM) i3 CPU M 350 @ 2.27GHz and RAM 3 GB. The user interface of GA implementation is shown in Figure 5:

\section{Results}

The Genetic Algorithm was executed based on the target of temperature set points in Table 2. The optimization generated error less than 0.01 and iteration less than 200. Those are based on 11 target of temperature set points. Iteration was achieved on 200 since the fitness value reached 200. Error of 0.01 was used since degree of target temperature used one digit after comma. Each of target temperature set points was tested 10 times. The optimization problem was solved by using real-coded GA. The population size was 10 . The maximum number of generation was 200 . The crossover rate was 0.6 . The mutation rate was 0.3 . The objective function was to minimize the difference between target temperature and generated by GA.

Solution from Genetic Algorithm was confirmed with the standard in Table 3. The confirmation results in Table 4 indicates the various solution which fit to the standard in Table 5. Table 6 indicated the optimal parameters of Genetic Algorithm solution based on standard (Table 5). The highest amount of solution was found in target temperature of $29^{\circ} \mathrm{C}$ and $30^{\circ} \mathrm{C}$, which have nine solutions.

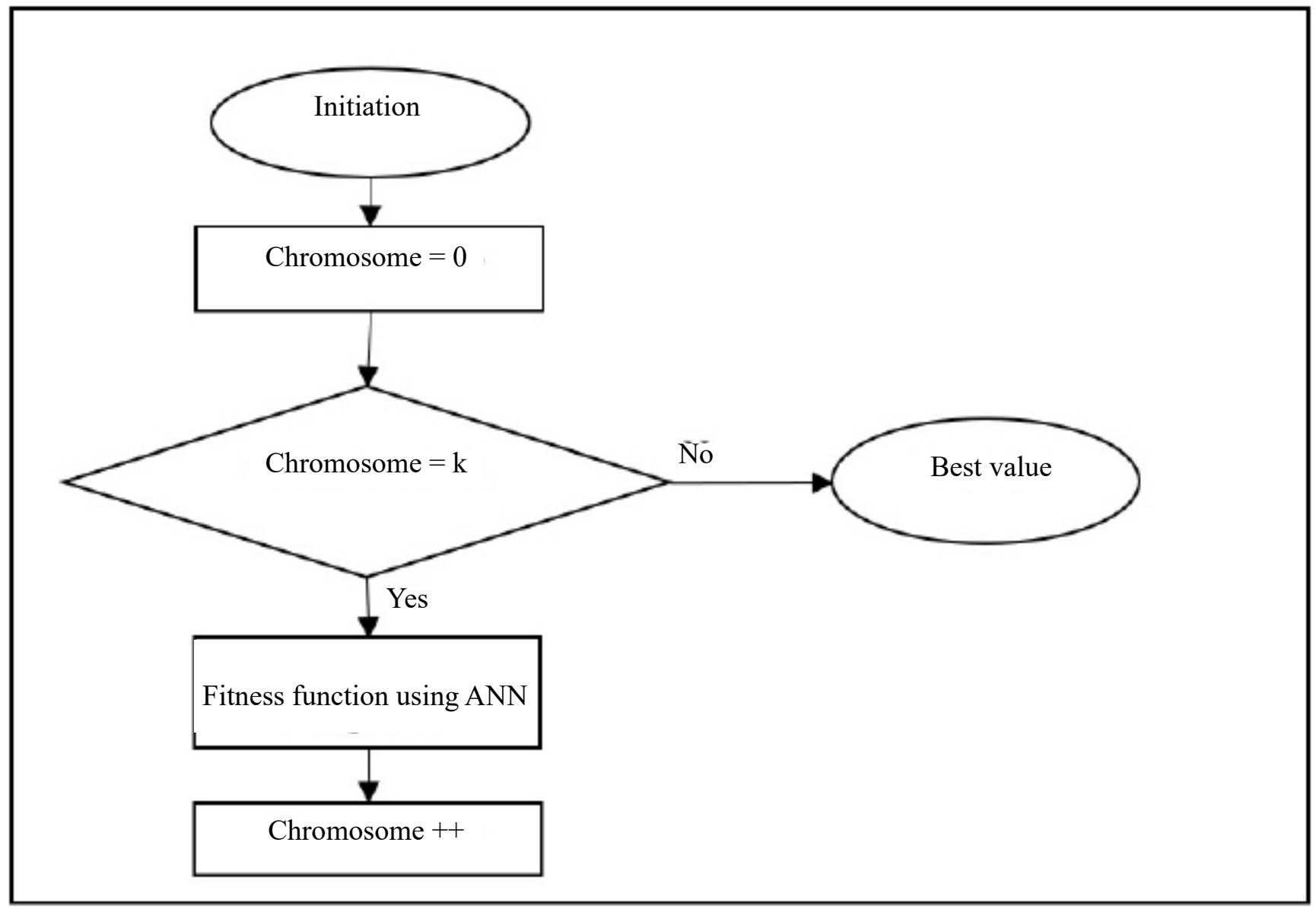

Figure 4. Flow chart of evaluation process 


\section{Best Chromosome}

Figure 5. User interface of the genetic algorithm system

Table 3. Environmental ergonomics set points based on modes value

\begin{tabular}{|c|c|c|c|c|c|c|c|c|c|c|c|}
\hline & 27.5 & 28.0 & 28.5 & 28.8 & 29.0 & 29.3 & 29.5 & 29.8 & 30.0 & 31.1 & 32.0 \\
\hline $\begin{array}{l}\mathrm{HR} \\
\end{array}$ & 80 & 117 & 103 & 92 & 98 & 89 & 111 & 119 & 85 & 117 & 117 \\
\hline $\mathrm{T}_{1}$ & 27 & 35 & 28 & 35 & 27 & 35 & 46 & 37 & 30 & 38 & 38 \\
\hline $\mathrm{RH}_{0}$ & 89 & 83 & 86 & 80 & 74 & 88 & 72 & 81 & 61 & 78 & 78 \\
\hline $\mathrm{RH}_{1}$ & 68 & 74 & 71 & 74 & 88 & 33 & 82 & 31 & 63 & 82 & 82 \\
\hline $\mathrm{L}_{\mathrm{b}}$ & 8509 & 6744 & 14655 & 2051 & 16634 & 14692 & 18306 & 5140 & 8497 & 9626 & 9626 \\
\hline
\end{tabular}

Table 4. Environmental ergonomics set points based on minimum error

\begin{tabular}{llllllllllll}
\hline & 27.5 & 28.0 & 28.5 & 28.8 & 29.0 & 29.3 & 29.5 & 29.8 & 30.0 & 31.1 & 32.0 \\
\hline $\mathrm{HR}$ & 122 & 73 & 91 & 105 & 99 & 110 & 88 & 83 & 105 & 81 & 86 \\
$\mathrm{~T}_{1}$ & 43 & 33 & 39 & 36 & 29 & 44 & 29 & 37 & 36 & 39 & 34 \\
$\mathrm{RH}_{0}$ & 92 & 87 & 91 & 80 & 82 & 90 & 76 & 76 & 83 & 87 & 77 \\
$\mathrm{RH}_{1}$ & 87 & 57 & 59 & 60 & 32 & 42 & 78 & 42 & 35 & 91 & 34 \\
$\mathrm{~L}_{1}$ & 17162 & 696 & 1813 & 2177 & 14074 & 2093 & 18459 & 590 & 3387 & 343 & 14285 \\
\hline
\end{tabular}

Table 5. Standard of environmental ergonomics parameters

\begin{tabular}{llll}
\hline Parameters & Classification & Range & References \\
\hline Heart rate (Pulse per minute) & Very light & $65-75$ & $\begin{array}{c}\text { (Anonym 1971) in } \\
\text { (Kolus et al. 2016) }\end{array}$ \\
& Light & $75-100$ & \\
Workplace Temperature $\left({ }^{\circ} \mathrm{C}\right)$ & Moderate & $100-125$ & (Anonym 2012) \\
& Recommendable & $18-30$ & \\
Workplace RH (\%) & Not recommendable & $>30$ & (Anonym 2011) \\
& Recommendable & $40-70$ & \\
Light intensity (Lux) & Not recommendable & $>70$ & (Anonym 2002) \\
& Recommendable & $<3000$ & \\
\hline
\end{tabular}


Table 6. Optimum parameters of GA solution based on standard (Table 5)

\begin{tabular}{|c|c|c|c|c|c|c|}
\hline Target $\left({ }^{\circ} \mathrm{C}\right)$ & No. & $\mathrm{HR}$ & $\mathrm{T}_{1}$ & $\mathrm{RH}_{0}$ & $\mathrm{RH}_{1}$ & $\mathrm{~L}_{1}$ \\
\hline 27.5 & 1 & 67 & 27 & 60 & 50 & 747 \\
\hline \multirow[t]{2}{*}{28.0} & 1 & 94 & 27 & 63 & 45 & 692 \\
\hline & 2 & 112 & 27 & 59 & 47 & 1730 \\
\hline \multirow[t]{3}{*}{28.5} & 1 & 102 & 29 & 61 & 66 & 1974 \\
\hline & 2 & 106 & 30 & 61 & 55 & 1004 \\
\hline & 3 & 116 & 29 & 60 & 66 & 2724 \\
\hline \multirow[t]{2}{*}{28.8} & 1 & 82 & 27 & 64 & 57 & 1763 \\
\hline & 2 & 69 & 29 & 62 & 54 & 1467 \\
\hline \multirow[t]{9}{*}{29.0} & 1 & 98 & 28 & 60 & 43 & 168 \\
\hline & 2 & 80 & 28 & 66 & 69 & 308 \\
\hline & 3 & 75 & 30 & 65 & 62 & 1752 \\
\hline & 4 & 119 & 28 & 62 & 49 & 2994 \\
\hline & 5 & 117 & 29 & 63 & 64 & 2635 \\
\hline & 6 & 97 & 30 & 69 & 54 & 2667 \\
\hline & 7 & 116 & 29 & 59 & 52 & 334 \\
\hline & 8 & 93 & 27 & 61 & 49 & 776 \\
\hline & 9 & 73 & 30 & 67 & 40 & 948 \\
\hline \multirow[t]{4}{*}{29.3} & 1 & 70 & 28 & 66 & 65 & 2688 \\
\hline & 2 & 87 & 29 & 63 & 67 & 2246 \\
\hline & 3 & 71 & 28 & 64 & 52 & 584 \\
\hline & 4 & 87 & 28 & 60 & 61 & 653 \\
\hline \multirow[t]{4}{*}{29.5} & 1 & 73 & 28 & 63 & 64 & 697 \\
\hline & 2 & 71 & 30 & 63 & 48 & 1715 \\
\hline & 3 & 121 & 27 & 61 & 52 & 1933 \\
\hline & 4 & 110 & 29 & 69 & 50 & 1484 \\
\hline \multirow[t]{4}{*}{29.8} & 1 & 77 & 28 & 63 & 44 & 2621 \\
\hline & 2 & 105 & 28 & 69 & 66 & 1991 \\
\hline & 3 & 87 & 27 & 65 & 49 & 2992 \\
\hline & 4 & 123 & 28 & 65 & 63 & 764 \\
\hline \multirow[t]{9}{*}{30.0} & 1 & 121 & 30 & 60 & 67 & 239 \\
\hline & 2 & 99 & 28 & 63 & 50 & 2102 \\
\hline & 3 & 83 & 30 & 65 & 52 & 1435 \\
\hline & 4 & 107 & 30 & 66 & 66 & 801 \\
\hline & 5 & 118 & 28 & 69 & 60 & 2756 \\
\hline & 6 & 110 & 27 & 65 & 44 & 1410 \\
\hline & 7 & 105 & 29 & 61 & 49 & 1753 \\
\hline & 8 & 111 & 27 & 68 & 44 & 1231 \\
\hline & 9 & 116 & 29 & 65 & 66 & 2892 \\
\hline \multirow[t]{4}{*}{31.1} & 1 & 108 & 30 & 64 & 61 & 2164 \\
\hline & 2 & 74 & 27 & 66 & 42 & 2763 \\
\hline & 3 & 121 & 29 & 64 & 55 & 2052 \\
\hline & 4 & 83 & 28 & 59 & 41 & 604 \\
\hline \multirow[t]{6}{*}{32.0} & 1 & 71 & 27 & 67 & 60 & 2040 \\
\hline & 2 & 88 & 30 & 63 & 50 & 1282 \\
\hline & 3 & 99 & 29 & 68 & 69 & 2312 \\
\hline & 4 & 70 & 27 & 60 & 58 & 2375 \\
\hline & 5 & 103 & 29 & 69 & 64 & 2696 \\
\hline & 6 & 102 & 27 & 67 & 67 & 704 \\
\hline
\end{tabular}

\section{Discussion}

\subsection{Optimum Environmental Ergonomics Parameter}

The design of environmental ergonomic assessment system, as shown in Figure 1, required the optimum values of workplace environment in bioproduction of food SMEs. The optimization model was developed using combination of GA and the weight of ANN. It is pursued on each chromosome by calculating the fitness value. The weight of ANN (Ushada et al. 2017b) was used to calculate the fitness function of GA. Each chromosome of GA represented the environmental ergonomics value. 
Therefore, Tables 3 and 4 indicates that GA could be used to search optimum set points of environmental ergonomics based on the predicted fitness values. Table 3 indicated the set points based on modes value while Table 4 is based on minimum error. Table 5 indicates the parameter standardization of environmental ergonomics. It was recapitulated from various literature review to support the quality control of digital ergonomics in food SMEs.

The standard parameter could be used by stakeholder of regional labor offices and SMEs cluster to monitor the appropriate environment for worker. In good practice of appropriate technology, a food SMEs could use a combination of controlled fan, air conditioner and KESAN $2^{\text {nd }}$ generation, to generate the standard optimum environmental ergonomics parameters. Since the characteristics of SME are flexible job scheduling and multi-tasking job description, it is recommended to have the various optimum parameters solution as shown in Table 6 . The future research suggested the classification of optimum workplace environmental parameters to generate the expected output status of poor, medium, and good ergonomics in design of environmental ergonomics assessment (Figure 1).

\section{Conclusion}

An environmental ergonomic assesment system was designed for Food SMEs. An optimization model for environmental ergonomic assesment in bioproduction of Food SMEs was developed using Genetic Algorithm. That model generated error less than 0.01 and iteration less than 200 based on 11 targets of temperature set points. Iteration was achieved on 200. The population size was 10 . The maximum number of generation was 200 . The crossover rate was 0.6 . The mutation rate was 0.3. The objective function was to minimize the difference between target temperature and generated by GA. The highest amount of solution was found in target temperature of $29^{\circ} \mathrm{C}$ and $30^{\circ} \mathrm{C}$, which have nine solutions. The various amount of solution was recommended to fit the characteristics of SME are flexible job scheduling and multi-tasking job description.

The standard of environmental ergonomics parameter in food SMEs were determined as optimum heart rate, indoor temperature, relative humidity before working, relative humidity after working, and light intensity. The set points was determined to attain the optimum environmental ergonomics based on target temperature of $29^{\circ} \mathrm{C}$ and $30^{\circ} \mathrm{C}$. In good practice of appropriate technology, a food SMEs could use a combination of controlled fan, air conditioner and KESAN $2^{\text {nd }}$ generation, to generate the standard optimum environmental ergonomics parameters.

\section{Acknowledgements}

This research was fully supported by Ministry of Research, Technology and Higher Education of the Republic of Indonesia by 2017 Research Grants of International Collaboration Competitive Research Grant for International Publication-Universitas Gadjah Mada 'Penelitian Kerjasama Luar Negeri dan Publikasi Internasional Tahun 2017" (No: SP DIPA042.06.1.401516/2017 and No: 2273/UN1.P.III/DITLIT/LT/2017).

\section{References}

Anonym, 1971. American Industrial Hygiene Association (AIHA) Ergonomic guide to assessment of metabolic and cardiac costs of physical work. In: Kolus A, Imbeau D, Dubé V, Dubeau D. Classifying work rate from heart rate measurements using an adaptive neuro-fuzzy inference system. App Ergon 54:158-168.

Anonym. 2002. Regulation of Ministry of Health Republic Indonesia No. 1405: Requirement of occupational health for office and industry. Jakarta: Ministry of Health Republic Indonesia.

Anonym. 2003. National Standar of Indonesia (SNI) No. 16-7063-2004: Threshold values of workplace environment, noise level, vibration of hand-upper arm and ultraviolet radiation. s.n.

Anonym. 2011. Regulation of Ministry of Health Republic Indonesia No. 1077: Healty Indoor Air at Home. Jakarta: Ministry of Health Republic Indonesia.

Anonym. 2012. Regulation of Ministry of Energy and Mineral Resources of Republic Indonesia No.13: Electricity Saving. Jakarta: Ministry of Energy and Mineral Resources of Republic Indonesia.

Delgoshaei A, Ali A. 2017. An applicable method for scheduling temporary and skilled-workers in dynamic cellular manufacturing systems using hybrid ant colony optimization and tabu search algorithms. Journal of Industrial and Producion Engineering 34:425-449.

Kolus A et al. 2016. Classifying work rate from heart rate measurements using an adaptive neuro-fuzzy inference system. App Ergon 54:158-168.

Ma L et al. 2017. Energy consumption optimization of high sulfur natural gas purification plant based on back propagation neural network and genetic algorithms. Energy Procedia 105:5166-5171.

Parsons KC. 2000. Environmental ergonomics: a review of principles, methods and models. App Ergon 31:581594.

Ushada M, Okayama T. 2016. Development of GreenAffective Work System for Food SMEs, Proceedings of International Conference of Agro-industry (ICoA). 
Ushada M et al. 2016. Integrated workload assesment sensor for agro-industrial production system (In Bahasa Indonesia: Alat penilai beban kerja terpadu di sistem produksi agroindustri). Patent Pending (Patent Application Indonesia No: P00201601182 on February 24, 2016).

Ushada M et al. 2017a. Identification of Environmental Ergonomics Control System for Indonesian SMEs. In: Proceedings of 2017 3rd International Conference on Control, Automation and Robotics. Nagoya:IEEE. pp. 453-456.

Ushada M et al. 2017b. Affective temperature control in food SMEs using Artificial Neural Network. Applied Artificial Intelligence 31:555-567.

Ushada M et al. 2017c. Sensor for temperature set points in agroindustrial production system (In Bahasa Indonesia: Alat penentu suhu acuan lingkungan kerja ergonomis di sistem produksi agroindustri). Patent Pending (Patent Application Indonesia No: P00201703623 on 8 Juni, 2017).
Ushada M. 2019. Digital Ergonomics Study To Support Work System of Food Agroindustry. Jurnal Teknologi dan Industri Pertanian Indonesia 11:6-10.

Wongwien T, Nanthavanij S. 2017. Priority-based ergonomic workforce schedulling for industrial workers performing hazardous jobs. Journal of Industrial and Production Engineering 34:52-60.

Yang J et al. 2015. Hybrid artificial neural network-genetic algorithm technique for condensing temperature control of air-cooled chillers. Procedia Engineering 121:706-713. 